\title{
Influenza Vaccine: Crucial now more than ever
}

\author{
Tarik Zahouani* and Magda Mendez \\ Department of Pediatrics, Lincoln Medical and Mental Health Center, USA
}

Submission: April 11, 2018; Published: May 03, 2018

*Corresponding author: Tarik Zahouani, Department of Pediatrics, Lincoln Medical Center, 237 East $149^{\text {th }}$ St Bronx, NY 10451 , USA, Tel: 718-579-5030; Email: TarikZahouani@gmail.com

\begin{abstract}
Influenza is still a significant cause of morbidity and mortality worldwide. 2018 is one of the deadliest seasons in the United States. Vaccination continues to be one of the major measures of prevention. We present two cases of siblings with mild persistent asthma and allergic rhinitis presenting with upper respiratory infection, one secondary to influenza and not receiving the influenza vaccine. A 5 year old Male with mild persistent asthma and allergic rhinitis presented to the emergency department with fever, cough, nasal congestion and difficulty breathing. Rapid influenza test was positive for influenza B. The patient did not receive the influenza vaccine. His sister, a 7 year old Female, also with mild persistent asthma and allergic rhinitis presented to the emergency department with fever, cough, and rhinorrhea for 2-3 days. Rapid influenza test was negative for influenza A and B. She received the influenza vaccine. In spite of the annual controversy regarding the effectiveness of the influenza vaccine, the immunization can prevent the infection and hospitalization and it is essential to the control of the disease.
\end{abstract}

\section{Case Report}

2018 influenza season has so far caused 133 child deaths with 16 deaths in the last week of January which is the most in a single week since the 2014-2015 seasons [1]. Vaccination remains a cornerstone in the prevention and control of influenza and it is strongly recommended for high risk group of complications such as pregnant women, elderly people, young children, people with chronic diseases, and occupational groups [2]. We present two cases of siblings with mild persistent asthma and allergic rhinitis that presented with upper respiratory infection, one secondary to influenza and not receiving the influenza vaccine.

\section{Case Presentation}

\section{Case 1}

A 5 year old Male with mild persistent asthma and allergic rhinitis presented to the emergency department (ED) with fever, cough, nasal congestion and difficulty breathing for one day. His 7y/o sister (Case 2) has been sick for 2-3 days. He had a temperature of $100.4^{\circ} \mathrm{F}$, heart rate of $107 \mathrm{beats} / \mathrm{min}$, respiratory rate of 20 breaths/min, blood pressure of $100 / 70 \mathrm{mmHg}$, and oxygen saturation of $100 \%$ on room air. On physical examination $(\mathrm{PE})$, the patient appeared well, was alert, oriented, in no acute distress and had mild expiratory wheezing. Heart, abdominal and the rest of the examination yielded normal findings. Rapid influenza test was positive for influenza B. The patient did not receive the influenza vaccine. The patient was treated with Oseltamivir for 5 days with resolution of the symptoms 5 days after the ED visit.

\section{Case 2}

A 7 year old Female with mild persistent asthma and allergic rhinitis presented to the emergency department (ED) with fever, cough, and rhinorrhea for 2-3 days. She had a temperature of $98.4^{\circ} \mathrm{F}$, heart rate of $102 \mathrm{beats} / \mathrm{min}$, respiratory rate of $20 \mathrm{breaths} /$ $\min$, blood pressure of $101 / 61 \mathrm{mmHg}$, and oxygen saturation of $100 \%$ on room air. On physical examination (PE), the patient appeared well, was alert, oriented, in no acute distress, had increase expiratory phase and pharyngeal erythema. Heart, abdominal and neurologic examination yielded normal findings. Rapid influenza test was negative for influenza A and B. The patient received the influenza vaccine 2 months prior to the visit to the ED. The patient symptoms resolved 2 days after the visit to the ED.

\section{Discussion}

After an incubation period of 1 to 3 days, most patients infected with influenza virus have uncomplicated illness, with sudden onset of fever, cough, headache, sore throat, rhinorrhea, nasal congestion, and muscle aches, which resolve over 3 to5 days, though cough and fatigue may persist longer. Children with influenza may have diarrhea and abdominal pain with respiratory symptoms. Influenza complications include exacerbation of chronic conditions such as asthma, chronic obstructive pulmonary disease, congestive cardiac failure and pneumonia. Severe complications can occur including bacterial 
coinfection, myocarditis, pericarditis, croup, bronchiolitis tracheitis, myositis, rhabdomyolysis, encephalopathy, and encephalitis. Influenza virus infection of the respiratory tract can trigger cytokine dysregulation, resulting in acute lung injury and fulminant progression to respiratory failure, acute respiratory distress syndrome, septic shock, acute kidney injury, and multiorgan failure [3].

Annual influenza vaccination is recommended for everyone6 months of age or older in the United states [4]. Prevention strategies for infant's younger than 6 months of age include vaccinating pregnant women and vaccinating all household members and care givers ("cocooning"). The effectiveness of influenza vaccine varies depending on several factors, including the recipient's age and immune response and the

match between circulating virus strains and vaccine strains. In recent years, influenza vaccine has been moderately effective, and some vaccinated persons may still develop influenza [4].

The 2018 influenza season is the deadliest season since the 2014-2015 seasons [1]. Influenza associated pediatric mortality in the United States for the last 4 seasons is shown in Table 1 [1].

Table 1: Influenza associated pediatric mortality in the United States 2014-2018 [CDC].

\begin{tabular}{|c|c|}
\hline Season & Total Deaths \\
\hline $2014-2015$ & 148 \\
\hline $2015-2016$ & 93 \\
\hline $2016-2017$ & 110 \\
\hline $2017-2018$ & 133 \\
\hline
\end{tabular}

Among the 4,562 children and adults with acute respiratory illness (ARI) studied from November 2, 2017, through February 3,2018 , a total of 1,712 (38\%) tested positive for influenza virus by reverse transcription polymerase-chain reaction, including 1,392 (81\%) influenza A viruses and 323 (19\%) influenza B viruses. The percentage of patients who were vaccinated ranged from $45 \%$ to $59 \%$ [5].

Multiple studies have demonstrated the influenza vaccine effectiveness in both the prevention of influenza illness and the prevention of hospitalization in children [6]. Both patients had mild persistent asthma and allergic rhinitis, and both presented with ARI. However the patient that was vaccinated did not have influenza and had a shorter course of illness.

\section{Conclusion}

Infection with influenza virus can have a deadly outcome especially in vulnerable pediatric patients with chronic disease such as asthma. Although the influenza vaccine effectiveness is a yearly controversial subject, the immunization can prevent the infection and hospitalization and it is essential to the control of the disease.

\section{References}

1. 2017-2018 Influenza Season Week 4 ending January 27, 2018. Weekly US Surveillance Report.

2. Influenza (seasonal). Fact sheet November 2016. World Health Organization, Geneva, Switzerland.

3. Writing Committee of the WHO Consultationon Clinical Aspects of Pandemic (H1N1) 2009 Influenza, Bautista E, Chotpitayasunondh T, Gao Z, Harper SA, et al. (2010) Clinical aspects of pandemic 2009 influenza A (H1N1) virus infection. N Engl J Med 362(18): 1708-1719.

4. Centers for Disease Control and Prevention (CDC) (2013) Prevention and control of seasonal influenza with vaccines: recommendations of the Advisory Committee on Immunization Practices--United States, 2013-2014. MMWR Recomm Rep 62(RR-07): 1-43.

5. Flannery B, Chung JR, Belongia EA, McLean HQ Gaglani M, et al. (2018) Interim Estimates of 2017-18 Seasonal Influenza Vaccine EffectivenessUnited States. MMWR Morb Mortal Wkly Rep 67(6): 180-185.

6. Sugaya N, Shinjoh M, Nakata Y, Tsunematsu K, Yamaguchi Y, et al. (2018) Three-season effectiveness of inactivated influenza vaccine in preventing influenza illness and hospitalizationin children in Japan, 2013-2016. Vaccine 36(8): 1063-1071.

\section{Your next submission with Juniper Publishers will reach you the below assets}

- Quality Editorial service

- Swift Peer Review

- Reprints availability

- E-prints Service

- Manuscript Podcast for convenient understanding

- Global attainment for your research

- Manuscript accessibility in different formats

( Pdf, E-pub, Full Text, Audio)

- Unceasing customer service

Track the below URL for one-step submission https://juniperpublishers.com/online-submission.php 